\title{
Description of a rat model of polymicrobial abdominal sepsis mimicking human colon perforation
}

\author{
Julia M. Utiger ${ }^{1}$, Michael Glas ${ }^{1}$, Anja Levis ${ }^{1,2}$, Josef Prazak and Matthias Haenggi ${ }^{1 *}$ (1)
}

\begin{abstract}
Objective: Standard rodent sepsis models as cecal ligation and puncture models (CLP) or cecal ligation and incision models (CLI) are frequently not suited experiments, mainly because they lack surgical repair, and they are difficult to control for severity. The colon ascendens stent peritonitis model (CASP) overcomes some of these limitations.

Result: Here we present our modification of the rodent CASP model, where severity of sepsis can be controlled by timing of surgical repair and treatment, and by diameter of the stent. Further, basic hemodynamic monitoring (blood pressure and heart rate) and frequent blood sampling can be achieved, which might guide further treatment.
\end{abstract}

Keywords: Rodent, Hemodynamic monitoring, Cecum, Colon, Ascending, Punctures, Peritonitis, Sepsis

\section{Introduction}

Sepsis is a life-threatening organ dysfunction due to a dysregulated host response to infection [1] and is associated with high mortality and unfavorable outcome $[2,3]$. Neither sepsis burden nor mortality has changed in the past decade [3]. Given the higher risk of acquiring sepsis and of adverse outcome in the elderly [4], with the aging population in many countries sepsis will remain and even will rise as one of the most important health care threats.

Since sepsis is a complex syndrome defined as organ dysfunction associated with dysregulated host response to infection [1, 4], preclinical research has to rely on animal models to explore the complex interaction of infectious agents and host factors. Commonly used research models are endotoxin/toxin administration, exogenously administered pathogenic bacteria, and host-barrier disruption models, where the animals' protective endogenous host barrier is altered. For practical and financial reasons, rodent models dominate over other species. The far most frequent models within this category are models where the intestinum is disrupted, and the intestinal content spills into the normally sterile peritoneal cavity and thus induces a polymicrobial sepsis. Cecal ligation and puncture (CLP models) and cecal ligation and incision (CLI models) are regarded as gold standard models because they resemble initiation and progression with characteristics of human sepsis, but this view has been challenged [5]. CLP and CLI do not completely mimic the representative course of human perforated intestine and are difficult to control in terms of severity and predictability. The colon ascendens stent peritonitis (CASP) model, first described in mice [6] and later in rats [7], overcomes this limitation.

In this manuscript, we describe the adaptations made to improve the CASP model in terms of monitoring hemodynamics and facilitating frequent blood sampling as well as non-surgical treatment.

\footnotetext{
*Correspondence: matthias.haenggi@insel.ch

${ }^{1}$ Department of Intensive Care Medicine, Bern University Hospital,

Inselspital, University of Bern, Bern, Switzerland

Full list of author information is available at the end of the article
}

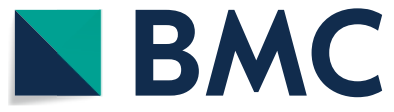

(c) The Author(s) 2021. This article is licensed under a Creative Commons Attribution 4.0 International License, which permits use, sharing, adaptation, distribution and reproduction in any medium or format, as long as you give appropriate credit to the original author(s) and the source, provide a link to the Creative Commons licence, and indicate if changes were made. The images or other third party material in this article are included in the article's Creative Commons licence, unless indicated otherwise in a credit line to the material. If material is not included in the article's Creative Commons licence and your intended use is not permitted by statutory regulation or exceeds the permitted use, you will need to obtain permission directly from the copyright holder. To view a copy of this licence, visit http://creativeco mmons.org/licenses/by/4.0/. The Creative Commons Public Domain Dedication waiver (http://creativecommons.org/publicdomain/ zero/1.0/) applies to the data made available in this article, unless otherwise stated in a credit line to the data. 


\section{Main text}

\section{Materials and methods}

These experiments were performed as a pilot of a project aiming to explore the effects of a new endotoxin scavenger as a randomized placebo-controlled trial, the results of the main experiments are not published in this manuscript.

The experiment was reviewed and approved by the Animal Care and Experimentation Committee of the Canton of Bern, Switzerland (26169 BE6/15) and followed the Swiss national guidelines for the performance of animal experiments. Male Wistar rats aged 8-9 weeks, weighing $380 \mathrm{~g}$ in average were obtained from Janvier Labs (Le Genest-Saint-Isle, France) and kept in individually ventilated cages (IVC) with controlled $12 \mathrm{~h}$ light/dark cycles at $22 \pm 2{ }^{\circ} \mathrm{C}$ at the Central Animal Facility of the University of Bern. Food and water were provided ad libitum. A total of 56 animals were included (4 groups: 20 animals sham surgery \pm scavenger/placebo, 36 animals $\mathrm{CASP} \pm$ scavenger/placebo).

\section{Anesthesia}

Anesthesia was induced with 6\% sevoflurane (Sevorane, AbbVie, Baar, Switzerland) in oxygen in an induction chamber, and $50 \mu \mathrm{g} / \mathrm{kg}$ fentanyl (Janssen-Cilag, Zug, Switzerland) was added intraperitoneally. The animals were intubated using a modified $2.0 \mathrm{~mm}$ Angiocath (BD, Allschwil; Switzerland) and mechanically ventilated with a small animal ventilator (KTR-4 Rodent Ventilator, Hugo Sachs, March, Germany). Anesthesia was maintained with sevoflurane $2.5-3.5 \%$, and analgesia with additional $50 \mu \mathrm{g} / \mathrm{kg}$ fentanyl administered subcutaneously $30 \mathrm{~min}$ later. The animal was placed on an operation table with an in-built feedback controlled heater system (TCAT-2, Harvard Apparatus, Hugo Sachs, March, Germany) aiming for a constant body temperature of $37^{\circ} \mathrm{C}$.

\section{Preparation}

After incision of the right groin, we tunneled two polyurethan catheters (PU 40, SAI Infusion Technologies, Lake Villa, IL, USA with a redon needle/wound drainage trocar from the neck to the groin.The catheters were then equipped with a 1.5 to $2 \mathrm{~cm}$ tip made of PE-50, and filled with heparinized sterile normal saline solution (5000 I.U. heparin in $1000 \mathrm{ml} \mathrm{NaCl} 0.9 \%$ ) via a blunt needle and luer lock syringe on the cranial part. The femoral artery and vein were microsurgically exposed, cannulated and secured with a suture. Before skin closure, the catheters were additionally bend as a loop and secured twice with sutures. The animals were turned in prone position and the catheters secured with a subcutaneous loop and suture at the neck. We channeled the catheters trough a tethered harness (SAI Infusion Technologies, Lake Villa,
IL, USA) and connected them via a two channel swivel with 2 purge systems (syringe drivers) to guarantee free movement of the animal and integrity of the catheters. After drawing a first arterial and venous blood sample, both purge lines were continuously flushed with $1.5 \mathrm{ml} / \mathrm{h}$ Glucose $5 \%$ in $\mathrm{H}_{2} \mathrm{O}$ 2:1 and heparin (5000 I.U. heparin in $1000 \mathrm{ml} \mathrm{GS}$ ), to the arterial line purge we added buprenorphine (Temgesic, Reckitt Benckiser Switzerland, Wallisellen) to achieve a concentration of $1 \mu \mathrm{g} / \mathrm{ml}$. The animals were weaned from the ventilator, extubated and placed for recovery from surgery in a cage equipped with a swivel mount. Duration of surgery was 50-60 min.

\section{Colon ascendens stent peritonitis}

6 hours after finishing the preparation the animals were re-anesthetized with sevoflurane $6 \%$ in oxygen, supplemented with $20 \mu \mathrm{g} / \mathrm{kg}$ buprenorphine subcutaneously. Anesthesia was maintained with 2.5 to $3.5 \%$ sevoflurane in oxygen via facemask. A median laparotomy was performed, and the coecum and the ascending colon identified and exposed. A small incision was made about $1 \mathrm{~cm}$ distal the iliocoecal valve at the anti-mesenterial side, and a 12 French PU catheter of $1.5 \mathrm{~cm}$ length was inserted. This stent was additionally fixed to the colon by a suture. Patency was tested by instillation of saline into the stent, with spontaneous emptying of feces afterwards, or gentle squeezing the coecum until intestinal content was visible in the opening of the stent. The animals in the sham group received the same surgery, omitting colostomy, with the stent only sutured at the outer side of the colon ascendens. The intestine was packed back into the abdominal cave and the abdominal wall was closed in two layers. Surgical time was below $20 \mathrm{~min}$. The animal was placed back into its cage equipped with the swivel mount. Volume replacement was started, the buprenorphine dosing was resumed. The animals were provided with water and nourishment ad libitum.

\section{Surgical repair and treatment}

16 hours after peritonitis induction and randomization, animals were again re-anesthetized as described before. The abdominal sutures were re-opened, the stent identified, which could necessitate exploration with sterile cotton swabs to remove fibrin and detritus. Cultures from the abundant purulent ascites and detritus were taken at this time point for the main experiment. Once the stent was identified, the additional suture was cut, the stent removed and the intestinal wall closed with simple interrupted stitchings. The abdominal cavity was then rinsed with warm Ringer's solution, and the abdominal wall closed with sutures. Surgical time was below $20 \mathrm{~min}$.

Then the rats were placed in their cages with the swivel mount. All animals received an intravenous infusion 
of meropenem (Meronem, Pfizer Switzerland, Zurich, $75 \mathrm{mg}$ per $\mathrm{kg} \mathrm{BW}$, diluted to $5 \mathrm{mg} / \mathrm{ml}$, in $15 \mathrm{~min}$ ) followed by a continuous infusion via the central venous line (225 mg/kg BW/24 h). Analgesia was provided continuously with buprenorphine administered via the intraarterial purge line.

Blood pressure was measured continuously with a standard transducer system linked to a BIOPAC MP100 analog-digital-converter and was acquired and analyzed with the Biopac AcqKnowledge Data Acquisition Software (BIOPAC, Goleta, CA 93117, USA). Heart rate was calculated with the blood pressure tracing.

Blood samples were drawn 16 and $40 \mathrm{~h}$ post peritonitis induction. After the last blood sampling the animals were euthanized by intravenous infusion of pentobarbital (150 mg/kg BW, Esconarkon, Streuli Pharma AG, Uznach, Switzerland).

\section{Results}

All but 2 animals survived the initial surgery. In the CASP group, 4 animals (out of 36) died or were euthanized according to the score sheet after sepsis induction, before randomization. No further premature death occurred after randomization and start of the treatment. Blood sampling was achieved before peritonitis induction and before start of meropenem $(6 \mathrm{~h})$ in all animals. Line patency decreased over time, after $24 \mathrm{~h}$, blood samples could not be obtained in 9 animals, but did not decrease further.

In the 6 animals where microbiological samples from the abdominal cavity were drawn at repair, polymicrobial growth of gram negative and gram positive bacteria in great quantity could be documented as a proof of the infection with intestinal pathogenes.

Because of the relatively long tubing system and connection via the swivel system, blood pressure tracings were damped, so. We relied on mean arterial pressure. Although clear signs of peritonitis were seen, and cultures grew abundant bacteria, systemic hypotension did not occur (mixed effects model for repeated measures data, $\mathrm{p}=\mathrm{ns}$, Fig. 1). Heart rate was significantly higher in the septic animals (mixed effects model, $p=0.005$ for group, $\mathrm{p}=0.02$ for time, group $\mathrm{x}$ time factor: $\mathrm{p}=0.04$, Fig. 2).

In conclusion, the addition of the arterial and venous catheters in the CASP model expands the research possibilities of the model. With these catheters, fluid management and anti-infective as well as analgesic treatment can be individualized, and blood sampling is facilitated. By analogy with known literature, where needle size, number of punctures and length of ligation modifies severity of sepsis [8], and in view of the experience with patients, where timing of repair is crucial, we believe that this

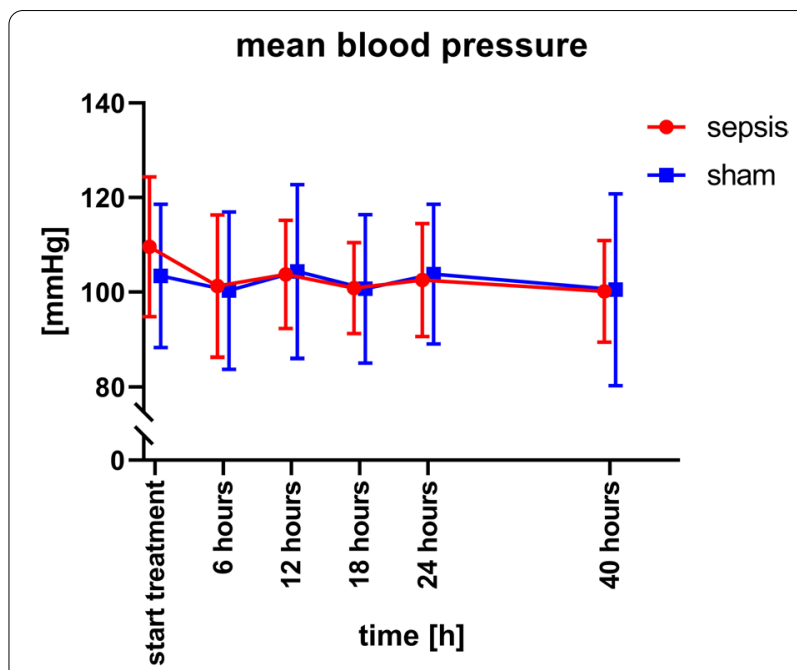

Fig. 1 Blood pressure. Time course of blood pressure und septic (red) and sham (blue) animals. Note that measurement of blood pressure began $16 \mathrm{~h}$ after sepsis induction /sham surgery, when treatment with surgery and meropenem started. There are no significant differences between the groups

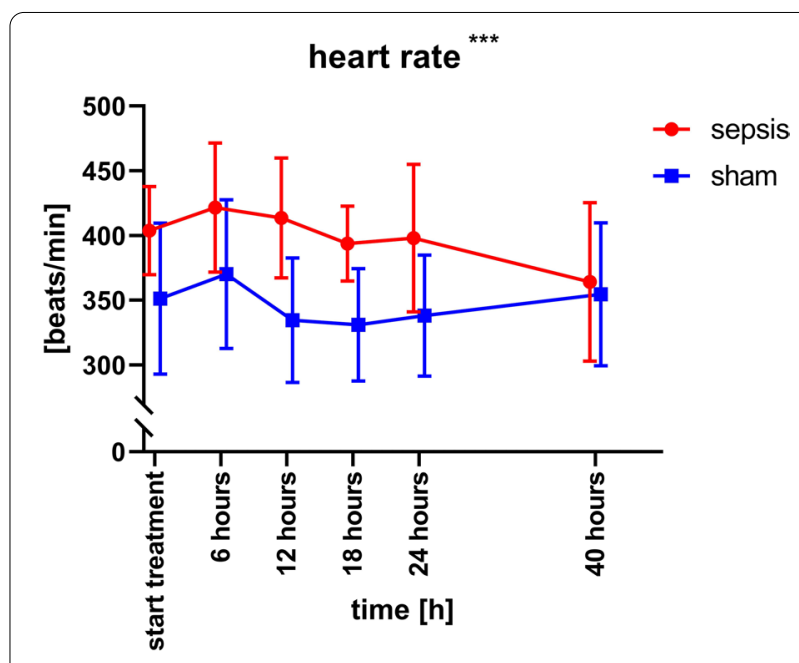

Fig. 2 Heart rate. Time course of heart rate und septic (red) and sham (blue) animals. Note that measurement of heart rate began $16 \mathrm{~h}$ after sepsis induction /sham surgery, when treatment with surgery and meropenem started. The difference between the groups is significant $(p=0.005)$

model can be used in a large variety of clinically relevant experiments.

\section{Limitation}

Traditional models have disadvantages depending on the research questions. Lipopolysaccharide injection models do not produce sepsis, but endotoxin shock; injection of bacteria or a defined amount of bacteria or 
fecal slurry lack the pathophysiology of gut discontinuation. In surgical models of abdominal sepsis abscess formation frequently occurs. This does not reflect the current medical scenario, where surgical treatment with closure of the gut discontinuation and lavage is attempted. The CASP model overcomes this drawback with surgical repair of the damage. Continuous bacterial contamination renders this model moderately controllable, but adaptation of the model can be accomplished by different sizes of the stent [9], and by different timing of surgical repair. Continuous blood pressure and heart rate monitoring can guide fluid management with frequent adjustments. Together with the venous catheter, both lines enable blood sampling without posing additional stress to the animal, and safe and reliable dosing of medication.

In this pilot experiment we found that combining the vessel cannulation and the CASP surgery in one single operation leads to an unacceptable high mortality. After modification and introducing a recovery period between both procedures the mortality during surgery declined. It is quite probable that the staged surgeries in this model induce inflammatory responses on its own and interfere with the results and outcomes on each step, but we have not quantified this effect. Another problem was failure to sample blood because of blocked catheters. Although we added heparin to the purge fluids, in some animals the catheter was partially clotted or developed a valve-like phenomena. With two lines in place, we could use the second line in some instances, but in $12 \%$, no blood sampling was possible. We recommend a tubing system with biocompatible heparin bonded surfaces, or adding an anticoagulant to the animal, which would in turn increase the risk of hemorrhage during septic shock.

Because of the long tubing and the connection with a swivel, the arterial blood pressure curve was damped. Since tissue perfusion depends on mean arterial blood pressure this is not a major drawback [10]. It could be criticized that this model did not produce relevant hypotonia and shock, as it would be expected in severe sepsis. Because of positive cultures of abundant bacteria with different species in the peritoneum, and the marked differences in heart rate between the septic and the sham animals, we are certain that sepsis and shock occurred, but treatment with intravenous fluids via purge lines and antibiotics prevented clinical deterioration and death.

A general problem in research is the use of younger animals, as we have done. Age is a well-known contributor to mortality in patients, and in animal models of sepsis [11]. Generalizability to the elderly human population may be challenging.

\section{Abbreviations}

CLP: Cecal ligation and puncture; CLI: Cecal ligation and incision models; CASP: Colon ascendens stent peritonitis.

\section{Acknowledgements}

We like to thank Sandra Nansoz, Research Lab of the Department of Intensive Care Medicine for her invaluable work preparing the experiments.

\section{Authors' contributions}

$J U$ developed the protocol, performed the experiments, analyzed the data and drafted the manuscript; MG conceived the study, performed the experiments, analyzed the data and drafted the manuscript, AL performed the experiments and drafted the manuscript, JP performed the experiments and drafted the manuscript, $\mathrm{MH}$ conceived the experiment, oversaw development of the protocol and was responsible for the overall conduct of the trial, helped analyzing the data and edited the manuscript. All authors read and approved the final manuscript.

\section{Funding}

The study was funded by departmental funds of the Department of Intensive Care Medicine, University Hospital Bern, University Bern.

\section{Availability of data and materials}

The datasets used and/or analyzed during the current study are available from the corresponding author on reasonable request.

\section{Ethics approval and consent to participate}

The experiment was reviewed and approved by the Animal Care and Experimentation Committee of the Canton of Bern, Switzerland (26169 BE6/15) and followed the Swiss national guidelines for the performance of animal experiments.

\section{Consent for publication \\ Not applicable.}

\section{Competing interests}

The Department of Intensive Care Medicine, University Hospital Bern, has, or has had in the past, research contracts with Orion Corporation, Abbott Nutrition International, B. Braun Medical AG, CSEM SA, Edwards Lifesciences Services GmbH, Kenta Biotech Ltd, Maquet Critical Care AB, Omnicare Clinical Research AG and research and development/consulting contracts with Edwards Lifesciences SA, Maquet Critical 3Care AB and Nestlé. The money was paid into a departmental fund; no author received personal financial gain. The Department of Intensive Care Medicine has received unrestricted educational grants from the following organizations for organizing a quarterly postgraduate educational symposium, the Berner Forum for Intensive Care (until 2015): Fresenius Kabi, GSK, MSD, Lilly, Baxter, Astellas, AstraZeneca, B | Braun, CSL Behring, Maquet, Novartis, Covidien, Nycomed, Pierre Fabre Pharma AG (formerly known as RobaPharm), Pfizer, Orion Pharma, Bard Medica S.A., Abbott AG and Anandic Medical Systems. The Department of Intensive Care Medicine has received unrestricted educational grants from the following organizations for organizing bi-annual postgraduate courses in the fields of critical care ultrasound, management of ECMO and mechanical ventilation: Pierre Fabre Pharma AG (formerly known as RobaPharm), Pfizer AG, Bard Medica S.A., Abbott AG, Anandic Medical Systems, PanGas AG Healthcare, Orion Pharma, Bracco, Edwards Lifesciences AG, Hamilton Medical AG, Fresenius Kabi (Switzerland) AG, Getinge Group Maquet AG, Dräger Schweiz AG, Teleflex Medical $\mathrm{GmbH}$.

\section{Author details}

${ }^{1}$ Department of Intensive Care Medicine, Bern University Hospital, Inselspital, University of Bern, Bern, Switzerland. ${ }^{2}$ Department of Anaesthesiology and Pain Medicine, Bern University Hospital, Inselspital, University of Bern, Bern, Switzerland.

Received: 20 October 2020 Accepted: 29 December 2020

Published online: 07 January 2021 


\section{References}

1. Singer M, Deutschman CS, Seymour CW, Shankar-Hari M, Annane D, Bauer M, Bellomo R, Bernard GR, Chiche J-D, Coopersmith CM, et al. The third international consensus definitions for sepsis and septic shock (Sepsis-3). JAMA. 2016;315(8):801-10.

2. Liu V, Escobar GJ, Greene JD, Soule J, Whippy A, Angus DC, Iwashyna TJ. Hospital deaths in patients with sepsis from 2 independent cohorts. JAMA. 2014;312(1):90-2.

3. Rhee C, Dantes R, Epstein L, Murphy DJ, Seymour CW, Iwashyna TJ, Kadri SS, Angus DC, Danner RL, Fiore AE, et al. Incidence and trends of sepsis in US hospitals using clinical vs claims data, 2009-2014. JAMA. 2017;318(13):1241-9.

4. Gotts JE, Matthay MA. Sepsis: pathophysiology and clinical management. BMJ. 2016;353:11585.

5. Dejager L, Pinheiro I, Dejonckheere E, Libert C. Cecal ligation and puncture: the gold standard model for polymicrobial sepsis? Trends Microbiol. 2011;19(4):198-208

6. Zantl N, Uebe A, Neumann B, Wagner H, Siewert JR, Holzmann B, Heidecke CD, Pfeffer K. Essential role of gamma interferon in survival of colon ascendens stent peritonitis, a novel murine model of abdominal sepsis. Infect Immun. 1998;66(5):2300-9.

7. Lustig MK, Bac VH, Pavlovic D, Maier S, Grundling M, Grisk O, Wendt M, Heidecke CD, Lehmann C. Colon ascendens stent peritonitis-a model of sepsis adopted to the rat: physiological, microcirculatory and laboratory changes. Shock. 2007;28(1):59-64.

8. Ruiz S, Vardon-Bounes F, Merlet-Dupuy V, Conil J-M, Buléon M, Fourcade $\mathrm{O}$, Tack I, Minville V. Sepsis modeling in mice: ligation length is a major severity factor in cecal ligation and puncture. Intensive Care Med Exp. 2016;4(1):22.

9. Maier S, Traeger T, Entleutner M, Westerholt A, Kleist B, Hüser N, Holzmann B, Stier A, Pfeffer K, Heidecke CD. Cecal ligation and puncture versus colon ascendens stent peritonitis: two distinct animal models for polymicrobial sepsis. Shock. 2004;21(6):505-11.

10. Leone M, Asfar P, Radermacher P, Vincent JL, Martin C. Optimizing mean arterial pressure in septic shock: a critical reappraisal of the literature. Crit Care. 2015;19(1):101.

11. Turnbull IR, Wizorek JJ, Osborne D, Hotchkiss RS, Coopersmith CM, Buchman TG. Effects of age on mortality and antibiotic efficacy in cecal ligation and puncture. Shock. 2003;19(4):310-3.

\section{Publisher's Note}

Springer Nature remains neutral with regard to jurisdictional claims in published maps and institutional affiliations.
Ready to submit your research? Choose BMC and benefit from:

- fast, convenient online submission

- thorough peer review by experienced researchers in your field

- rapid publication on acceptance

- support for research data, including large and complex data types

- gold Open Access which fosters wider collaboration and increased citations

- maximum visibility for your research: over $100 \mathrm{M}$ website views per year

At BMC, research is always in progress.

Learn more biomedcentral.com/submissions 